\title{
Profile of Ectopic Pregnancy at Kathmandu Model Hospital
}

\section{Pradhan HK, Dangal G, Karki A, Shrestha R, Bhattachan K}

${ }^{1}$ Department of Obstetric and Gynaecology, Kathmandu Model Hospital, Nepal.

Received: February 3, 2015 ; Accepted: August 5, 2015

Aims: The study was done to analyze the epidemiology, diagnosis and treatment aspect of patients with ectopic pregnancy at Kathmandu Model Hospital.

Methods: This was a retrospective study of patients with ectopic pregnancy who received treatment at Kathmandu Model Hospital from January 2008 to September 2015. Data were analyzed from patient records and discharge summary. Delivery number was obtained from maternity record.

Results: There were 61 cases of ectopic pregnancy with the hospital incidence of $1.46 \%$. Highest number of patients 20 $(32.79 \%)$ were in the age range of 28-32 years. Most of the patients were nullipara $22(36.06 \%)$ or with parity two 20 (32.79\%). Some risk factors were found in $29(47.54 \%)$ cases. The commonest risk factor was pelvic inflammatory disease in 12 (19.67\%). All presented with pain abdomen, 48 (78.68\%) had per vaginal bleeding, 17 (27.87\%) presented in shock. Cervical excitation was present in $38(62.29 \%)$. Urine for pregnancy test was positive in all and $37(60.66 \%)$ had ultrasonography. Ten $(16.39 \%)$ patients underwent emergency laparoscopic surgery and $40(65.57 \%)$ had emergency laparotomy. Salpingectomy was required in $53(86.89 \%)$ cases. The average hospital stay was 5 days.

Conclusions: The study showed that ectopic pregnancy could occur at any reproductive age without obvious risk factors. Although not all patients gave history of amenorrhoea, pain abdomen was present in all.

Keywords: ectopic pregnancy; pain abdomen; shock.

\section{INTRODUCTION}

Ectopic pregnancy is implantation of fertilized ovum in an area other than the endometrial lining of uterus. ${ }^{1}$ Approximately $1-2 \%$ of all naturally conceived pregnancies end up with ectopic pregnancy. ${ }^{2}$ It is the leading cause of maternal mortality in the first trimester of pregnancy. ${ }^{3}$ Ectopic pregnancy accounts for $9 \%$ of all pregnancy related death. ${ }^{1}$ The morbidity and mortality associated with ectopic pregnancy are directly influenced by the time elapsed between the onset of symptoms and start of treatment. ${ }^{4}$

Several risk factors are associated with ectopic pregnancy. History of pelvic inflammatory disease (PID) has been shown to be the strongest predictor. ${ }^{5}$ The development of sensitive $\beta$-hCG assay, increasing use of ultrasonography and laparoscopy has allowed earlier diagnosis of ectopic pregnancy. ${ }^{1}$ The objective of the present study was to analyze the incidence, risk factors, epidemiological characteristics and management of ectopic pregnancy at Kathmandu Model Hospital.

\section{CORRESPONDENCE}

Dr Hema Kumar Pradhan

Department of Obstetrics and Gynaecology, Kathmandu Model Hospital, Nepal

Email: drhemapradhan@hotmail.com

Phone: +977-9849375252

\section{METHODS}

This was a retrospective study done from January 2008 to September 2015 at Kathmandu Model Hospital. Permission for the study and ethical clearance were taken from the Institutional Review Committee of Public Health Concern Trust-NEPAL/Kathmandu Model Hospital. The data of all patients admitted during this period with the diagnosis of ectopic pregnancy were collected from patients' files and discharge records. Data on age, parity, risk factors, diagnostic methods, treatment, operative findings, etc. were analyzed. Total number of delivery during this period was noted from the maternity records of the hospital.

\section{RESULTS}

There were 61 cases of ectopic pregnancies out of 4161 live births during the study period with the incidence of $1.46 \%$. The majority 36 (59.01\%) were from Kathmandu, 8 (13.11\%) from Kirtipur, $5(8.19 \%)$ from Bhaktapur and $12(19.67 \%)$ were from outside the valley. Highest number of patients $20(32.79 \%)$ were in the age range of $28-32$ years (Figure 1). 


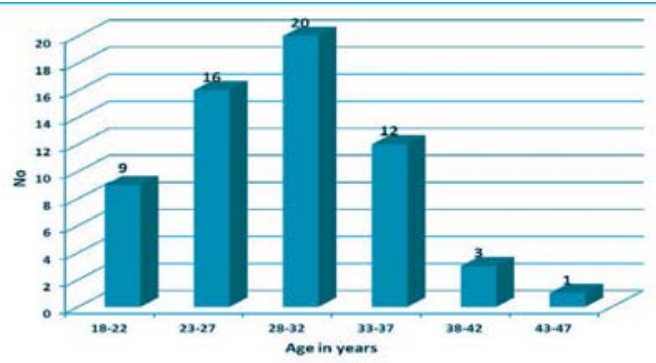

Figure 1. Age distribution of cases $(n=61)$.

Marital status of cases is shown in Figure 2.

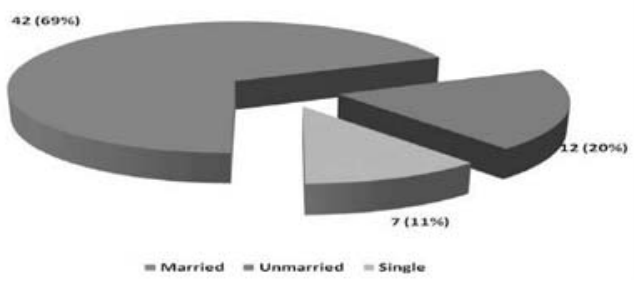

Figure 2. Marital status of cases $(n=61)$.

Most of the patients were nullipara 22 (36.06\%) followed by parity two in 20 cases $(32.79 \%)$ (Table1). Twenty-nine $(47.54 \%)$ patients had risk factors like previous ectopic pregnancy, previous abortions, pelvic inflammatory disease (PID). Thirty-two $(52.46 \%)$ had no obvious risk factors (Table 1$)$. Nine patients had undergone manual vacuum aspiration and three had medical abortion at other center for the missed diagnosis.

Table 1. Reproductive, gynecological history and risk factors of cases $(n=61)$.

\begin{tabular}{|ll|}
\hline Reproductive history & Number (\%) \\
\hline $\mathrm{P}_{0}$ & $22(36.06)$ \\
$\mathrm{P}_{1}$ & $14(22.95)$ \\
$\mathrm{P}_{2}$ & $20(32.79)$ \\
$\mathrm{P}_{3}$ and above & $5(8.20)$ \\
Risk factors & \\
$\mathrm{PID}$ & $12(19.67)$ \\
Previous abortion & $7(11.47)$ \\
Previous LSCS & $4(6.56)$ \\
Subfertility treatment & $3(4.92)$ \\
Previous ectopic & $2(3.28)$ \\
Copper T in-situ & $1(1.64)$ \\
No obvious risk factor & $32(52.46)$ \\
\hline
\end{tabular}

Clinical features on presentation are shown in Table 2. History of pain abdomen was present in all cases and 17 cases $(27.87 \%)$ presented in shock/collapse. Urine for pregnancy test (UPT) was positive in all cases. Ultrasonography was done on $37(60.66 \%)$ cases, which showed various amounts of hemoperitoneum and adnexal masses suggestive of ectopic pregnancy. Seven (11.48\%) had hemoglobin less than $5 \mathrm{gm} \%$ (Table 2). Diagnosis on admission was ectopic pregnancy in $54(88.52 \%)$, acute pelvic inflammatory disease (PID) in $5(8.19 \%)$ and chocolate cyst in 2 $(3.28 \%)$ cases.

Table 2. Clinical features and investigations on admission $(n=61)$.

\begin{tabular}{|ll|}
\hline Clinical features & Number (\%) \\
\hline Amenorrhoea & $42(68.85)$ \\
PV bleeding & $48(78.69)$ \\
Pain abdomen & $61(100)$ \\
Shock & $17(27.87)$ \\
Abdominal tenderness & $61(100)$ \\
Cervical excitation & $38(62.29)$ \\
Adnexal mass on pelvic examination & $9(14.75)$ \\
Investigations & \\
UPT & $61(100)$ \\
USG & $37(60.66)$ \\
Hemoglobin in gm\% & \\
\multicolumn{1}{c}{$<5$} & $7(11.47)$ \\
$\quad 8$ to 7 & $17(27.87)$ \\
$\quad$ above 10 & $16(26.23)$ \\
& $21(34.43)$ \\
\hline
\end{tabular}

One patient was treated conservatively with injection Methotrexate. She improved and was discharged after 3 days. Laparoscopy was done in 10 (16.39\%) and emergency laparotomy was done in $40(65.57 \%)$ cases. One patient required total abdominal hysterectomy and right salphingoophorectomy as she had previous ectopic pregnancy and all pelvic structures were adherent. Twenty-two cases (36.07\%) had rightsided tubal pregnancy and 31 cases $(50.82 \%)$ had left sided tubal pregnancy. Milking was done in 3 cases (4.92\%) and cornual wedge resection was done in 3 cases $(4.92 \%)$ \{ Table 3 . The most common site of ectopic pregnancy in our series was the ampulla in 50 $(81.97 \%)$ cases (Table 3$)$. 
Table 3. Treatment and operative findings in cases $(n=61)$.

\begin{tabular}{|ll|}
\hline Treatment & Number (\%) \\
\hline Laparotomy and right salphingectomy & $18(29.51)$ \\
Laparotomy and left salphingectomy & $25(40.98)$ \\
TAH with RSO & $1(1.64)$ \\
Milking of POC & $3(4.92)$ \\
Cornual wedge resection & $3(4.92)$ \\
Laparoscopy and right salpingectomy & $4(6.56)$ \\
Laparoscopy and left salpingectomy & $6(9.84)$ \\
Conservative (Methotrexate) & $1(1.64)$ \\
Rupture site & \\
Tubal abortion & $2(3.28)$ \\
Cornual ectopic & $3(4.92)$ \\
Isthmus & $5(8.20)$ \\
Ampulla & $50(81.97)$ \\
Site unknown & $1(1.64)$ \\
\hline
\end{tabular}

Various amount of hemoperitoneum was observed during operation. The highest amount was more than two liters in 15 cases $(24.59 \%)$ \{Table 4$\}$. Most of the patients $(24.59 \%)$ required four units of blood transfusion. No transfusion was required in 28 cases (45.90\%). The highest number of blood transfusion was six units in $3(4.92 \%)$ patients, five units of blood was transfused to $1(1.64 \%)$, three units to 1 (1.64\%) and two units to $13(21.31 \%)$ patients. The patients who presented in shock had largest amount of hemoperitoneum on operation and they required more amount of blood transfusion.

The range of hospital stay was 3-7 days with average hospital stay of 5 days. Five $(8.20 \%)$ patients had longest hospital stay of 7 days. Six $(9.84 \%)$ were discharged on $6^{\text {th }}$ day, $28(45.90 \%)$ on $5^{\text {th }}$ day, 10 $(16.39 \%)$ on $4^{\text {th }}$ day. Twelve $(19.67 \%)$ patients had short hospital stay of 3 days. The patients who presented in shock and required more amount of blood transfusion had longest hospital stay, whereas who were treated laparoscopically and conservatively had shortest hospital stay. There was no mortality. Table 4. Hemoperitoneum in cases $(n=61)$.

\begin{tabular}{|ll|}
\hline Blood loss & Number (\%) \\
\hline $30 \mathrm{ml}$ (calculated by USG) & $1(1.64)$ \\
$<500 \mathrm{ml}$ & $20(32.79)$ \\
$500-999 \mathrm{ml}$ & $11(18.03)$ \\
$1000-1499 \mathrm{ml}$ & $6(9.84)$ \\
$1500-1999 \mathrm{ml}$ & $8(13.11)$ \\
$>2000 \mathrm{ml}$ & $15(24.59)$ \\
\hline
\end{tabular}

\section{DISCUSSION}

The incidence of ectopic pregnancy in our study was $1.46 \%$ which is comparable to $1.14 \%$ in a study by Abdulaziz $^{6}$ and $1.74 \%$ in another study by Jabbar. ${ }^{7}$ The peak age was 28-32 years in our study which is comparable to that from BP Koirala Institute of Health Sciences (BPKIHS) which was 26-30 years. ${ }^{8}$ In a study done in Nepal Medical College Teaching Hospital (NMCTH), peak age range was 20-35years. ${ }^{4}$ The rising incidence in young women is due to the fact that they are more sexually active. ${ }^{9}$ In our study $36.07 \%$ were nullipara whereas in the study of NMCTH, $49 \%$ were nullipara. In the same study, the gestational age range was 5-11weeks with mean of 6.9 weeks. ${ }^{4}$ In our series, gestational age range was 5-12 weeks with majority $(37.70 \%)$ in 6 weeks which are comparable. In our study $4.92 \%$ had amenorrhoea for more than 10 weeks but in the study of BPKIHS $1.3 \%$ had amenorrhoea for more than 10 weeks. ${ }^{8}$ In our study all the patients had pain abdomen, $68.85 \%$ had history of amenorrhoea and $78.69 \%$ had pervaginal bleeding which is comparable to $97.3 \%$ pain abdomen, $73.6 \%$ amenorrhoea and $57.8 \%$ pervaginal bleeding in a study conducted in Pakistan. ${ }^{10}$ In the present study, $27.87 \%$ presented in shock. In the study of BPKIHS, ${ }^{8} 12 \%$ were in shock and in the study done in India by Majhi et al, ${ }^{11} 9.4 \%$ were in shock. The difference may be due to the fact that patients who come from outside valley take a longer time to reach hospital. In this study $86.89 \%$ had ruptured ectopic which is comparable to $82.6 \%$ in the study of BPKIHS. ${ }^{8}$ In the study of Majhi et al ${ }^{11}$ $70.2 \%$ had ruptured ectopic pregnancy.

Although the exact etiology of ectopic pregnancy is not well understood, several risk factors have been found to be associated with it. The risk factors are tubal surgery, documented tubal pathology, previous ectopic pregnancy, infertility, pelvic inflammatory disease, multiple sexual partners, previous pelvic or abdominal surgery and exogenous hormones. ${ }^{1}$ In our study, $47.5 \%$ had risk factors which is comparable to $40 \%$ in the study of Jabbar et al. ${ }^{7}$ Our study also showed that $19.67 \%$ had pelvic inflammatory disease, $4.92 \%$ had subfertility, $3.28 \%$ had previous history of ectopic pregnancy, $6.56 \%$ had previous caesarean section, $1.64 \%$ had copper $\mathrm{T}$ in-situ. In a study in Pakistan by Shah et al, ${ }^{10}$ risk factor was higher $(60.5 \%)$. History of subfertility was $23.6 \%$, previous 
ectopic pregnancy was $7.8 \%$ copper $\mathrm{T}$ was $2.6 \%$, previous caesarean section was $10.5 \%$.,abdominal tuberculosis $15.7 \%$, tubal surgery $2.8 \%$, dilatation and curettage $18.4 \%$, injection depo provera $10.5 \%$ and oral contraceptive pills was in $7.8 \%$. In the study by Majhi et al $^{11}$ there was identifiable risk factors in $65 \%$ of cases. History of tubectomy was $14.5 \%$, previous abortion was $26.1 \%$, infertility $12.2 \%$, pelvic inflammatory disease $12.8 \%$ and previous surgery was $11.1 \%$. The variation is due to difference in sample size.

In our series, urine pregnancy test was positive in all. However, the study of Abound et $\mathrm{al}^{12}$ showed $11 \%$ false negative result. Diagnostic error was $11.48 \%$ in our study whereas in another study by Alsulieman et $\mathrm{al}^{13}$ it was $35.9 \%$. The disparity was due to larger sample size and not using ultrasonography as additional diagnostic tool. In this study $98.08 \%$ had tubal pregnancy which is comparable to $98 \%$ in another study. ${ }^{14}$ Methotrexate was given in $1.64 \%$ in our study, whereas in the study of BPKIHS $2.6 \%$ received methotrxate. ${ }^{8}$

In the present study, $86.89 \%$ required salpingectomy, but salpingectomy was done in $69.3 \%$ and salpingoophorectomy in $17.5 \%$ in the study of BPKIHS. ${ }^{8}$ We had no ovarian pregnancy so ovary was salvaged in our series. In BPKIHS 1.3\% had ovarian pregnancies ${ }^{8}$ and why more number of

\section{REFERENCES}

1. Uzelac PS, Garmel SH. Early pregnancy risks. In: DeCherney AH, Nathan L, editors. Current obstetric and gynecologic diagnosis and treatment. $10^{\text {th }}$ ed. New York: McGraw-Hill; 2007. P. 259-72.

2. Shaw JL, Dey SK, Critchley HO, Horne AW. Current knowledge of the aetiology of human tubal ectopic pregnancy. Hum Reprod Update. 2010;16:432-44.

3. Farquhar CM. Ectopic pregnancy. Lancet. 2005;366:583-91.

4. Pradhan P, Thapamagar SB, Maskey S. A profile of ectopic pregnancy at Nepal Medical College Teaching Hospital. Nepal Med Coll J. 2006;8(4):238-42.

5. Hadgu A, Koch G, Weström L. Analysis of ectopic pregnancy data using marginal and conditional models. Statist Med.1997;16:2403-17.

6. Abdulaziz Al-Turki H. Trends in ectopic pregnancies in eastern Saudi Arabia. ISRN Obstetrics and Gynecology. Volume 2013. http://dx.doi.org/10.1155/2013/975251

7. Jabbar FA, Al-Wakeel M. A study of 45 cases of ectopic pregnancy. Int J Gynaecol Obstet. 1980;18(3):214-7.

8. Jha P, Uprety D, Banerjee B. Ectopic pregnancy - two years review from BPKIHS, Nepal. Kathmandu Univ Med J. 2005;3(4):365-9 salpingooporectomy was done was not explained. In our study $54.09 \%$ cases required blood transfusion whereas in another study from BPKIHS ${ }^{8}, 70.6 \%$ cases required blood transfusion. In the study of Madagaskar ${ }^{15}$ only $27.1 \%$ needed blood transfusion. The requirement of blood transfusion depended on the status at the time of presentation and the amount of hemoperitoneum. In BPKIHS ${ }^{8}$ the patients were from remote areas and majorities were from low socioeconomic group and presented late. There was no case fatality in our study. In another study, two case fatalities were reported. This may be due to large sample size. ${ }^{16}$

\section{CONCLUSIONS}

The study showed that ectopic pregnancy could occur at any reproductive age even without obvious risk factors. There may not be history of amenorrhoea neither the patients be in shock. Mannagement included conservative with methotrexate, laparotomy and laparoscopy. If any woman of reproductive age presents with unexplained acute abdomen, irrespective of history of amenorrhoea, ectopic pregnancy must be ruled out.

\section{DISCL OSURE}

The authors report no conflicts of interest in this work.

No violation of human rights and safety.

Funding: Nil

9. Raj KM, Glass MR, Rutherfor AJ. Trends in the incidence of ectopic pregnancy in England and Wales from 1966-1996. Brit J Obstet Gynaecol. 2000;107:369-74.

10. Shah N, Khan NH. Ectopic pregnancy: presentation and risk factors. J Coll Physicians Surg Pak. 2005;15(9):535-8.

11. Majhi AK, Roy N, Karmakar KS, Banerjee PK. Ectopic pregnancy-an analysis of 180 cases. J Indian Med Assoc. 2007;105(6):308-10.

12. Aboud E, Chaliha C. Nine year survey of 138 ectopic pregnancies. Arch Gynecol Obstet. 1998;261(2):83-7.

13. Alsuleiman SA, Grimes EM. Ectopic pregnancy: a review of 147 cases. J Reprod Med. 1982;27(2):101-6.

14. Aboud E. A five-year review of ectopic pregnancy. Clin Exp Obstet Gynecol. 1997;24(3):127-9.

15. Randriambololona DM, Anjaharisoaniaina NT, Rekoronirina EB, Harioly MO, Randriambelomanana JA, Andrianampanalinarivo RH. Ectopic pregnancy in Madagascar: 107 cases. Med Sante Trop. 2012;22(4):394-7.

16. Gonzalez FA, Waxman M. Ectopic pregnancy: a retrospective study of 501 consecutive patients. Diagn Gynecol Obstet. 1981;3(3):181-6. 